\title{
Relationship between the presence of bronchiectasis and acute exacerbation in Thai COPD patients
}

This article was published in the following Dove Press journal: International Journal of COPD

\author{
Theerasuk Kawamatawong' \\ Jitsupa Onnipa' \\ Thitiporn \\ Suwatanapongched ${ }^{2}$ \\ 'Department of Medicine, \\ Ramathibodi Hospital, Mahidol \\ University, Bangkok, Thailand; \\ ${ }^{2}$ Department of Diagnostic and \\ Therapeutic Radiology, Ramathibodi \\ Hospital, Mahidol University, Bangkok, \\ Thailand
}

Correspondence: Theerasuk Kawamatawong

Department of Medicine, Ramathibodi Hospital, Mahidol University, Rama

6 Road, Phayathai, Rachathewi District, Bangkok 10400, Thailand

Tel +66022011619

Fax +66022011629

Email ktheerasuk@hotmail.com
Background: The prevalence rate of bronchiectasis in COPD is variable. Coexisting bronchiectasis and COPD may influence COPD severity and exacerbation.

Objective: We investigated whether bronchiectasis is associated with frequent or severe COPD exacerbation. Lower airway bacterial and mycobacterial infections are a possible mechanism for bronchiectasis.

Materials and methods: A cross-sectional study was conducted in 2013-2014. COPD exacerbations and hospitalizations were reviewed. Spirometry and CT were performed. COPD symptoms were assessed by using the COPD assessment test (CAT) and modified Medical Research Council (mMRC) dyspnea scale. Sputum inductions were performed and specimens were sent for microbiology.

Results: We recruited 72 patients. Global Initiative for Chronic Obstructive Lung Disease (GOLD) A, B, C, and D, were noted in $20 \%, 27.1 \%, 14.3 \%$, and $38.6 \%$ of the patients, respectively. Frequent exacerbations $(\geq 2)$ and/or $\geq 1$ hospitalization in the previous year were observed in $40.3 \%$ of patients. Median mMRC of COPD with frequent and non-frequent exacerbations was 1.0 (range 1-2) and 2.0 (range 1-3), ( $p=0.002)$, respectively. Median CAT of COPD with frequent and non-frequent exacerbations was 20.5 (3-37) and $11.0(2-32),(p=0.004)$, respectively. CT-detected bronchiectasis was observed in $47.2 \%$ of patients. Median mMRC of COPD with and without bronchiectasis was $1.0(0-4)$ and $1.0(0-4)(p=0.22)$, respectively. Median CAT of COPD with and without bronchiectasis was 16.2 (95\% CI: 12.9-19.6) and 13.0 (3-37), $(p=0.49)$, respectively. The lower post-bronchodilator forced expiratory volume in 1 second $\left(\mathrm{FEV}_{1}\right)$ of COPD with frequent exacerbations than those without was noted $(p=0.007)$. The post-bronchodilator forced expiratory volume at 1 second percent in patients with and without bronchiectasis was not different ( $p=0.91$ ). After adjusting for gender, severity of airflow obstruction, severity of COPD symptoms, the odds ratio for bronchiectasis with frequent and/or severe exacerbation was 4.99 (95\% CI: 1.31-18.94), ( $p=0.018)$. Neither bacterial nor mycobacterial airway infection was associated with bronchiectasis or frequent exacerbation.

Conclusions: Bronchiectasis is common in Thai COPD. It was associated with frequent exacerbation or hospitalization. Mycobacterial tuberculosis in COPD patients with bronchiectasis was uncommon.

Keywords: prevalence, bronchiectasis, COPD, computed tomography, exacerbation, sputum, bacteria, mycobacterium

\section{Introduction}

COPD exacerbation affects patients morbidity and mortality. ${ }^{1-3}$ Exacerbation of COPD is defined by an acute, sustained worsening of patient's condition beyond normal dayto-day variation and warrants a change in medication. ${ }^{4,5}$ Severity of airflow limitation 
and history of exacerbations in the year are associated with an increased risk of future exacerbations. ${ }^{3}$ Furthermore, chronic mucus hypersecretion in COPD or chronic bronchitis, has been identified as a risk factor of COPD exacerbation. ${ }^{6}$ However, the symptoms of cough and phlegm production are common in bronchiectasis. Bronchiectasis causes permanent destruction of the bronchi, and is associated with increased sputum production and susceptibility to infected complications. ${ }^{7,8}$ Bronchiectasis combined with COPD has been recognized as a COPD phenotype. However, the prevalence of bronchiectasis in Thai COPD patients is unknown. ${ }^{9}$ CT has been widely used for detecting bronchiectasis..$^{9,10}$ Specific lung structural abnormalities, including bronchiectasis, predict meaningful clinical outcome of COPD. ${ }^{11}$ The mechanisms that link bronchiectasis and COPD are unclear and remain to be determined. ${ }^{12}$

Bronchiectasis was identified in $4 \%$ of COPD patients in the multinational Evaluation of COPD Longitudinally to Identify Predictive Surrogate Endpoints (ECLIPSE). ${ }^{13}$ Bronchiectasis is more prevalent in the more severe COPD according to Global Initiative for Chronic Obstructive Lung Disease (GOLD) stages. ${ }^{3}$ Combined bronchiectasis and COPD have been investigated with regard to clinical significance and therapeutic application. ${ }^{14}$ In Southeast Asia, including Thailand, non-cystic fibrosis bronchiectasis is mainly caused by post-infectious disease and tuberculosis. ${ }^{15}$ Accordingly, the present study aims to identify the prevalence of bronchiectasis in Thai COPD patients. The association of bronchiectasis with COPD exacerbation and mycobacterial infection with the COPD combined with bronchiectasis phenotype were investigated.

\section{Objective}

We investigated whether CT-detected bronchiectasis is associated with frequent COPD exacerbation or hospitalization. We also examined lower airway bacterial and mycobacterial airway infections as putative mechanisms of bronchiectasis in Thai COPD patients.

\section{Methods}

\section{Study subjects}

COPD was diagnosed in participants aged 40 years old or more. COPD patients presented with significant symptoms, exposure to risk factors of COPD, and persistent airflow obstruction according to GOLD guideline. ${ }^{4}$ All the COPD patients were current or ex-smokers ( $\geq 10$ packyears). The persistent airflow limitation was confirmed by post-bronchodilator forced expiratory volume in 1 second $\left(\mathrm{FEV}_{1}\right) /$ forced vital capacity $(\mathrm{FVC})$ ratio of $<0.7$. $^{4}$

\section{Spirometry and reversibility testing}

Spirometry and bronchodilator reversibility testing were performed according to the American Thoracic Society/ European Respiratory Society (ATS/ERS) standard practice. Salbutamol $400 \mu \mathrm{g}$ was used for reversibility testing. ${ }^{16}$ Adjustment of the normal or predictive value for Asian subjects in terms of age, sex, and height was done. The patients who were unable to perform spirometry adequately were excluded.

\section{Definition of COPD exacerbation}

COPD exacerbation was clinically defined according to the International Classification of Disease, 10th Revision, and the Anthonisen criteria. ${ }^{17}$

\section{Classification of COPD exacerbation patients}

COPD patients were divided into 2 groups; non-frequent exacerbation, and frequent or severe exacerbation. Those who had 0-1 exacerbation/year were classified as non-frequent exacerbation patients, and those who had $\geq 2$ exacerbations/ year were classified as frequent exacerbation patients. Severe exacerbation patients required at least 1 hospitalization owing to COPD exacerbation in the previous year. ${ }^{4}$

\section{Assessment COPD symptoms}

COPD symptoms were assessed by using the Thai version COPD Assessment Test (CAT) and/or modified Medical Research Council (mMRC) dyspnea scale. ${ }^{18-20}$ The more symptomatic COPD patients were those who had either a CAT score of $\geq 10$ or a mMRC scale of $\geq 2$. COPD patients were classified GOLD COPD A, B, C, and D according to the GOLD 2014 multidimensional approach using COPD symptoms and exacerbation history or post-bronchodilator $\mathrm{FEV}_{1} \%$ predicted. $^{4}$

\section{Patient recruitment}

COPD patients were recruited during the stable phase of the disease, which we defined as lack of evidence of exacerbation for at least 4 weeks. All patients signed an informed consent agreement to participate in the clinical study. This study was approved by the Committee on Human Right Related to Research Involving Human Subjects, Faculty of Medicine Ramathibodi Hospital, Mahidol University.

\section{Diagnosis of bronchiectasis}

All COPD patients had CT scan performed during the stable phase of the disease. Stable COPD was defined by the absence of COPD exacerbation in the past 4 weeks. All CT scans were performed on a 64 multidetector row CT scanner 
(SOMOTOM Sensation 64, Siemens Healthcare, Erlangen/ Munich, Germany). Helical CT scan was performed in the craniocaudal direction and supine position. All CT images were reconstructed with section thickness and section interval of $1.0 \mathrm{~mm}$ and $0.7 \mathrm{~mm}$ or $2.0 \mathrm{~mm}$ and $2.0 \mathrm{~mm}$, respectively. All images were reviewed by an experienced board-certified radiologist. Pulmonary and airway abnormalities were defined according to Fleischner Society glossary of terms for thoracic imaging. Morphologic criteria of bronchiectasis was considered when there was bronchial dilatation with respect to the accompanying pulmonary artery (the signet ring sign), lack of bronchial tapering (the tram-track sign) or identification of bronchi within $1 \mathrm{~cm}$ of the peripheral surface. The bronchiectasis was further classified as tubular, varicose or cystic type, depending on the appearance of the affected bronchi. Emphysema was considered when there was focal area of low attenuation, usually without visible wall. Emphysema was further subclassified as centrilobular, paraseptal, or panlobular depending on the location and distribution of the affected lungs. Other radiographic findings included bullae, bleb, atelectasis, pulmonary nodules, mass and interstitial pulmonary fibrosis; small airways abnormalities, including centrilobular branching opacities or tree-in-bud pattern reflecting mucus filled bronchiolectasis and air trapping; large airways abnormalities (expiratory collapse of the trachea and large bronchi $>50 \%$ during dynamic forced expiration). Extra-pulmonary findings, including calcified lymph nodes and cardiovascular abnormalities (aortic calcification, coronary calcification, and evidence of pulmonary hypertension) were also recorded. ${ }^{21}$

Isotonic saline or $0.9 \%$ normal saline solution $(0.9 \% \mathrm{NSS}$ weight per volume) was delivered via micropump ultrasonic nebulization (Aeroneb ${ }^{\circledR}$, Aerogen, Galway, Ireland) for sputum induction. Standard volume of $2 \mathrm{~mL} 0.9 \%$ NSS was administered for 30 minutes. ${ }^{22}$ Sputum specimens were obtained and processed for microbiological study. Acid-fast bacilli (AFB) staining was undertaken using a modified Ziehl-Neelsen method, bacterial pathogen morphology was identified using Gram stain. Results of staining were reported as positive AFB in the presence of 1-9 bacilli/100 oil immersion fields. In addition, we performed aerobic culture using standard culture media. To identify lower airway bacterial colonization, we qualitatively assessed positive bacterial growth. We performed mycobacterial culture and used Lowenstein-Jensen Media to detect mycobacteria colonies. Standard biochemical tests were later undertaken for identification of the species.

\section{Statistical analysis}

STATA statistical package was used for statistical analysis. Continuous variables were expressed using means, SDs and medians as appropriate, for normal distribution. The association of 2 categorical data was assessed using the Pearson chi-square test. We obtained odds ratios (ORs) and $95 \%$ CIs for independent variables. A $p$-value of $<0.05$ was considered to be statistically significant.

\section{Results}

In all, 72 consecutive patients were recruited from the chest clinic of Ramathibodi Hospital. They had a mean age of $72.4 \pm 1.06$ years, and 62 were men. The mean post-bronchodilator $\mathrm{FEV}_{1}$ was $60 \% \pm 2.5 \%$ predicted. The symptom severity of COPD was presented by CAT and mMRC with a mean of $15 \pm 1.11$ and $1.64 \pm 1.07$, respectively. We classified $20 \%, 27.1 \%, 14.3 \%$ and $38.6 \%$ of COPD patients as GOLD A, B, C, and D, respectively. Significant COPD exacerbation ( $\geq 2$ episodes/year or at least 1 COPDrelated hospitalization in the previous year) was observed in 29 cases $(40.28 \%)$. The median (interquartile range [IQR]) CAT score of COPD patients with frequent and non-frequent exacerbations was 20.5 (3-37) and 11.0 (2-32), respectively ( $p=0.0037)$. The mean mMRC scale of patients with frequent exacerbations was 2.17 (95\% CI: 1.68-2.67), the mean mMRC with non-frequent exacerbations was 1.3 (95\% CI: 1.07-1.53), which was considered to be a statistically significant difference $(p=0.0022)$.

Median (IQR) post-bronchodilator $\mathrm{FEV}_{1} \%$ in $\mathrm{COPD}$ patients with frequent exacerbations was 51.69\% (30.0-78.0) and post-bronchodilator $\mathrm{FEV}_{1} \%$ predicted in $\mathrm{COPD}$ patients with non-frequent exacerbations was $65.38 \%$ (43.0-88.0). The post-bronchodilator $\mathrm{FEV}_{1} \%$ was also significantly different in patients with and without frequent exacerbations $(p=0.007)$. Table 1 shows the characteristics of COPD patients with frequent exacerbation of COPD $(n=29)$ and non-frequent exacerbation group $(n=43)$.

Table I Demographic and baseline details of subjects, including symptoms and functional characteristics

\begin{tabular}{llll}
\hline $\begin{array}{l}\text { Patients' } \\
\text { characteristics }\end{array}$ & $\begin{array}{l}\text { Non-frequent } \\
\text { exacerbation } \\
(\mathbf{n}=\mathbf{4 3})\end{array}$ & $\begin{array}{l}\text { Frequent } \\
\text { exacerbation } \\
(\mathbf{n}=\mathbf{2 9})\end{array}$ & p-value \\
\hline $\begin{array}{l}\text { Gender, male (female) } \\
\text { Age (years) }\end{array}$ & $42(1)$ & $23(6)$ & 0.015 \\
Post-bronchodilator $^{\mathrm{a}}$ & $73.39(60.0-85.0)$ & $70.96(59.0-82)$ & 0.264 \\
FEV \% predicted $^{\mathrm{a}}$ & $65.38(43.0-88.0)$ & $51.69(30.0-78.0)$ & 0.007 \\
CAT score $^{\mathrm{a}}$ & $11.0(2-32)$ & $20.5(3-37)$ & 0.003 \\
mMRC $^{\mathrm{a}}$ & $1.0(\mathrm{I}-2)$ & $2.0(1-3)$ & 0.002 \\
\hline
\end{tabular}

Notes: a Median and IQR. Data are presented as median, IQR and proportion (\%). The statistical significance was determined by $p$-value $<0.05$.

Abbreviations: CAT, COPD assessment test; $\mathrm{FEV}_{1}$, forced expiratory volume in I second; IQR, interquartile range; mMRC, modified Medical Research Council Dyspnea Scale. 
Table 2 Association between bronchiectasis, gender, severe COPD symptoms (CAT $\geq 10$ ), more dyspnea, severity of airflow limitation and frequent COPD exacerbation ( $\geq 2$ in the past year) and/or hospitalized exacerbation in the past year

\begin{tabular}{|c|c|c|c|c|c|c|}
\hline \multirow[t]{3}{*}{ Variables } & \multicolumn{3}{|c|}{ Univariate analysis } & \multicolumn{3}{|c|}{ Multivariate analysis } \\
\hline & Odds & $95 \% \mathrm{Cl}$ & $p$-value & Odds & $95 \% \mathrm{Cl}$ & $p$-value \\
\hline & \multicolumn{3}{|l|}{ ratio } & \multicolumn{3}{|l|}{ ratio } \\
\hline Male gender & 0.09 & $0.01-0.805$ & 0.008 & 0.08 & $0.007-0.834$ & 0.035 \\
\hline Post-BD FEV,$\geq 50 \%$ predicted & 0.21 & $0.07-0.61$ & 0.003 & 0.11 & $0.025-0.443$ & 0.002 \\
\hline CAT score $\geq 10$ & 2.90 & $0.98-8.59$ & 0.005 & 1.43 & $0.347-5.952$ & 0.615 \\
\hline mMRC scale $\geq 2$ & 2.33 & I.37-3.94 & 0.0006 & 3.36 & $0.89-12.65$ & 0.07 \\
\hline Bronchiectasis & 2.76 & $1.04-7.29$ & 0.037 & 4.99 & $1.31-18.94$ & 0.018 \\
\hline
\end{tabular}

Notes: The dependent variable is the frequent COPD exacerbation ( $\geq 2$ in the past year) and/or hospitalization due to exacerbation in the past year in 72 patients (binary variables). Each independent variable was adjusted for gender, severity of airflow obstruction (post-BD FEV $\geq 50 \%$ predicted), severity of COPD symptoms (CAT $\geq 10$ ), severity of dyspnea symptoms ( $\mathrm{mMRC} \geq 2$ ) and bronchiectasis. The statistical significance was determined by $p$-value $<0.05$.

Abbreviations: BD, bronchodilator; CAT, COPD assessment test; FEV , forced expiratory volume in I second; mMRC, modified Medical Research Council Dyspnea Scale.

Bronchiectasis with different severities was detected using CT in 34 cases (47.22\%). Bronchiectasis was present in 18 patients $(62.07 \%)$ of the frequent exacerbation group and in 16 patients $(37.21 \%)$ of the non-frequent exacerbation group. There was a significant difference between the proportions of patients with CT-detected bronchiectasis with the frequent COPD exacerbations and patients without bronchiectasis $(p=0.038)$. The OR of CT-detected bronchiectasis in the frequent exacerbation group was 2.76 (95\% CI: 1.04-7.3). After covariates, including gender, severity of airflow obstruction (post-bronchodilator $\mathrm{FEV}_{1} \%$ predicted) and COPD symptoms (CAT score and mMRC) were adjusted using multivariate analysis. The OR of bronchiectasis for COPD exacerbation was 4.99 (95\% CI: $1.31-18.94)$ as shown in Table 2.

The median (IQR) of CAT score of COPD patients with and without bronchiectasis was 13.0 (3-37) and 13.0 (2-32), respectively. The median (IQR) or mMRC of COPD patients with and without bronchiectasis was $1.0(0-4)$ and $1.0(0-4)$, respectively. The presence of bronchiectasis was not significantly associated with more symptomatic COPD, defined by either the CAT score or mMRC scale, compared with the group without bronchiectasis. The median (IQR) post-bronchodilator $\mathrm{FEV}_{1} \%$ predicted of COPD patients with computed tomography (CT)-detected bronchiectasis was $59.50 \%(44.50-77.0)$, and it was not different from that of patients without bronchiectasis at $60.0 \%(46.0-75.25)$ $(p=0.91)$, as shown in Table 3 .

A total of 72 COPD patients from the entire cohort performed sputum induction. However, the unacceptable and contaminated sputum specimens from bacterial culture were reported in 62 cases (86.1\%). The presence of positive bacterial culture from the induced sputum was identified in 9 cases (12.5\%). Pseudomonas aeruginosa and Acinetobacter baumannii were commonly recovered pathogens from aerobic culture of sputum specimens $(4.16 \%)$. Furthermore, the presence of positive mycobacterial culture from the induced sputum was identified in 8 cases $(11.11 \%)$. However, we did not find an association between positive mycobacterial culture and positive aerobic culture in sputum with the presence of CT-detected bronchiectasis. Bacterial and mycobacterial pathogens isolated from subjects with frequent and nonfrequent COPD exacerbations are shown in Table 4.

Among COPD cohort, cystic, varicose, and tubular bronchiectasis were noted in 10 patients $(24.39 \%), 15$ patients (36.58\%), and 27 patients (65.85\%), respectively. More than

Table 3 Symptoms and physiological conditions of COPD patients with and without bronchiectasis

\begin{tabular}{|c|c|c|c|}
\hline Parameters & $\begin{array}{l}\text { Patients without CT- } \\
\text { detected bronchiectasis } \\
(\mathrm{N}=38)\end{array}$ & $\begin{array}{l}\text { Patients with } \mathrm{CT} \text { - } \\
\text { detected bronchiectasis } \\
(\mathrm{N}=34)\end{array}$ & $p$-value \\
\hline Age $\left(\right.$ years) ${ }^{\mathrm{a}}$ & $75.0(69.0-79.5)$ & $71.0(63.0-78.0)$ & 0.14 \\
\hline Post-bronchodilator $\mathrm{FEV}, \%$ predicted ${ }^{a}$ & $59.50(44.50-77.0)$ & $60.0(46.0-75.25)$ & 0.91 \\
\hline CAT score ${ }^{a}$ & $13.0(3-37)$ & $13.0(2-32)$ & 0.49 \\
\hline mMRC scale ${ }^{a}$ & $1.0(0-4)$ & $1.0(0-4)$ & 0.22 \\
\hline $\begin{array}{l}\text { COPD exacerbations } \geq 2 \text { years or } \\
\text { hospitalizations } \geq 1 \text { year } n(\%)\end{array}$ & II (37.93\%) & $18(62.07 \%)$ & 0.038 \\
\hline
\end{tabular}

Notes: aMedian and IQR. Data are presented as median, IQR and proportion (\%). The statistical significance was determined by $p$-value $<0.05$.

Abbreviations: CAT, COPD assessment test; $\mathrm{FEV}_{1}$, forced expiratory volume in I second; CT, computed tomography; IQR, interquartile range; mMRC, modified Medical Research Council Dyspnea Scale. 
Table 4 Proportion of bacterial and mycobacterial pathogens isolated from the sputum of COPD patients, including isolated pathogens in patients with and without frequent or severe exacerbation

\begin{tabular}{|c|c|c|c|c|}
\hline Parameter & $\begin{array}{l}\text { Total } \\
(n=72)\end{array}$ & $\begin{array}{l}\text { COPD with non-frequent } \\
\text { exacerbation }(\mathrm{N}=43)\end{array}$ & $\begin{array}{l}\text { COPD with frequent } \\
\text { exacerbation }(n=29)\end{array}$ & $p$-value \\
\hline Bronchiectasis, n (\%) & $34(47.2)$ & $16(37.2 \%)$ & 18 (62.1\%) & 0.038 \\
\hline Bacterial colonization, n (\%) & $9(12.5)$ & $4(9.3 \%)$ & 5 (17.24\%) & 0.47 \\
\hline Pseudomonas aeruginosa, $\mathrm{n}(\%)$ & $3(4.16)$ & $2(4.56)$ & I (3.45) & \\
\hline Acinetobacter baumannii, n (\%) & $3(4.16)$ & 0 & $3(10.34)$ & \\
\hline Klebsiella pneumoniae, n (\%) & $2(2.78)$ & I (2.32) & I (3.45) & \\
\hline Streptococcus viridans, n (\%) & I (I.38) & 0 & I (3.45) & \\
\hline Mycobacterial growth, n (\%) & $8(11.11)$ & $6(13.95)$ & $2(6.9)$ & 0.35 \\
\hline
\end{tabular}

Notes: Data are presented as proportion (\%). The statistical significance was determined by $p$-value $<0.05$.

one pattern of bronchiectasis was observed in COPD patients.

The bronchiectasis with different severities were detected on $\mathrm{CT}$ as shown in Figures 1, 2A-C, 3A-B, and 4A-C. We detected 59 cases (81.94\%) of pulmonary emphysema in this study. Emphysema was radiologically classified as centrilobular emphysema, and paraseptal and panlobular emphysema in $34(57.62 \%)$ and 14 cases (23.72\%), respectively. Centrilobular emphysema is shown in Figures 3A-B and $4 \mathrm{~A}-\mathrm{C}$. Combined pulmonary emphysema and bronchial wall thickening was also noted from imaging studies, as shown in Figure 5. Coronary calcification was an extra-pulmonary finding detected by CT in 60 of our cases (83.33\%) as shown in Figure 6A-C. Axial CT images with a mediastinalwindow setting showed a dilated main pulmonary artery (6A) and aortic and coronary artery calcification (6B and C). We determined no significant association in this COPD cohort between the symptoms defining a CAT score $\geq 10$ and the presence of coronary calcification. Other common CT findings were lymph node enlargement, solid and ground-glass pulmonary nodules, tree-in-bud appearance, and tracheobronchomalacia. Details of CT abnormalities are shown in Table 5.

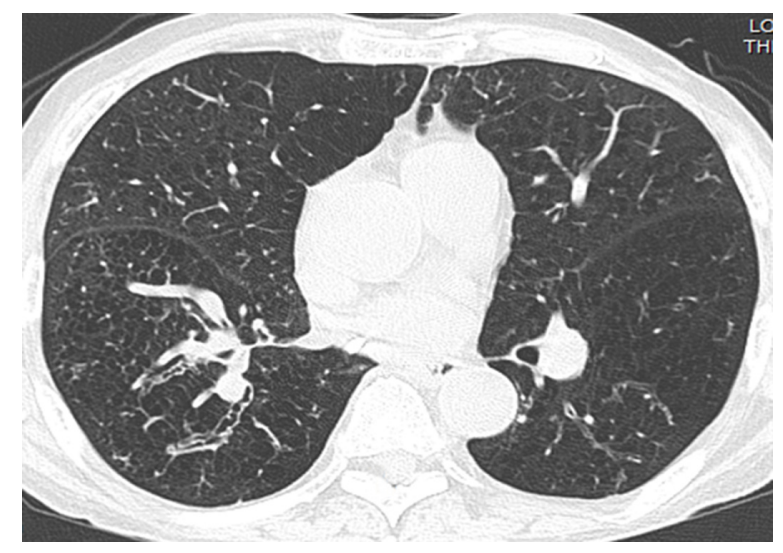

Figure I Axial CT image with a lung-window setting showing diffuse emphysema with varicose bronchiectasis in the right lower lobe and tubular bronchiectasis in the left lower lobe.

Abbreviation: CT, computed tomography.

\section{Discussion}

CT has been widely accepted and used as an imaging modality for evaluating bronchiectasis. ${ }^{23}$ Half (47.22\%) of COPD patients had co-existing bronchiectasis, detected by CT in our study. In addition, frequent COPD exacerbations of $\geq 2$ year or at least 1 hospital admission for acute COPD exacerbation in the previous year was associated with bronchiectasis (OR 4.99; 95\% CI: 1.31-18.94; $p=0.018$ ). Similar associations of bronchiectasis with COPD have been noted in previous studies. ${ }^{8,9,13,24}$ Martinez-Garcia et al have shown that the presence of bronchiectasis was associated with severe airflow obstruction and at least 1 COPD exacerbation requiring hospital admission in the past year. ${ }^{24} \mathrm{In}$ contrast, only $4 \%$ of patients in the ECLIPSE cohort were found to have bronchiectasis. In addition, the prevalence of bronchiectasis was observed to increase with the GOLD stages. ${ }^{3}$

Frequent exacerbations of COPD is the strongest predictor of poor prognosis in COPD patients, and is associated with a progressive decline in lung function. ${ }^{3}$ In addition, Donaldson et al reported faster decline in $\mathrm{FEV}_{1} \%$ in patients with frequent exacerbations. ${ }^{25}$ Hence, frequent exacerbations have been a predictor of prognosis in COPD patients. Links between bronchiectasis and poor COPD outcome have been emphasized in epidemiological studies, including the present investigation, in terms of frequent and severe COPD exacerbation. However, effect of bronchiectasis on the rapid lung function decline has not been evaluated and requires a prospective investigation.

Inflammatory and infectious damage to the airways leads to airway destruction in bronchiectasis. ${ }^{7,12}$ Common isolated microorganisms were $P$. aeruginosa $(4.16 \%)$ and $A$. baumannii (4.16\%) in our cohort. These findings are similar to the previous report of Martinez-Garcia et al. ${ }^{24} P$. aeruginosa was the most common pathogenic organism in that study. Bacterial colonization of the airway is a predisposing factor 

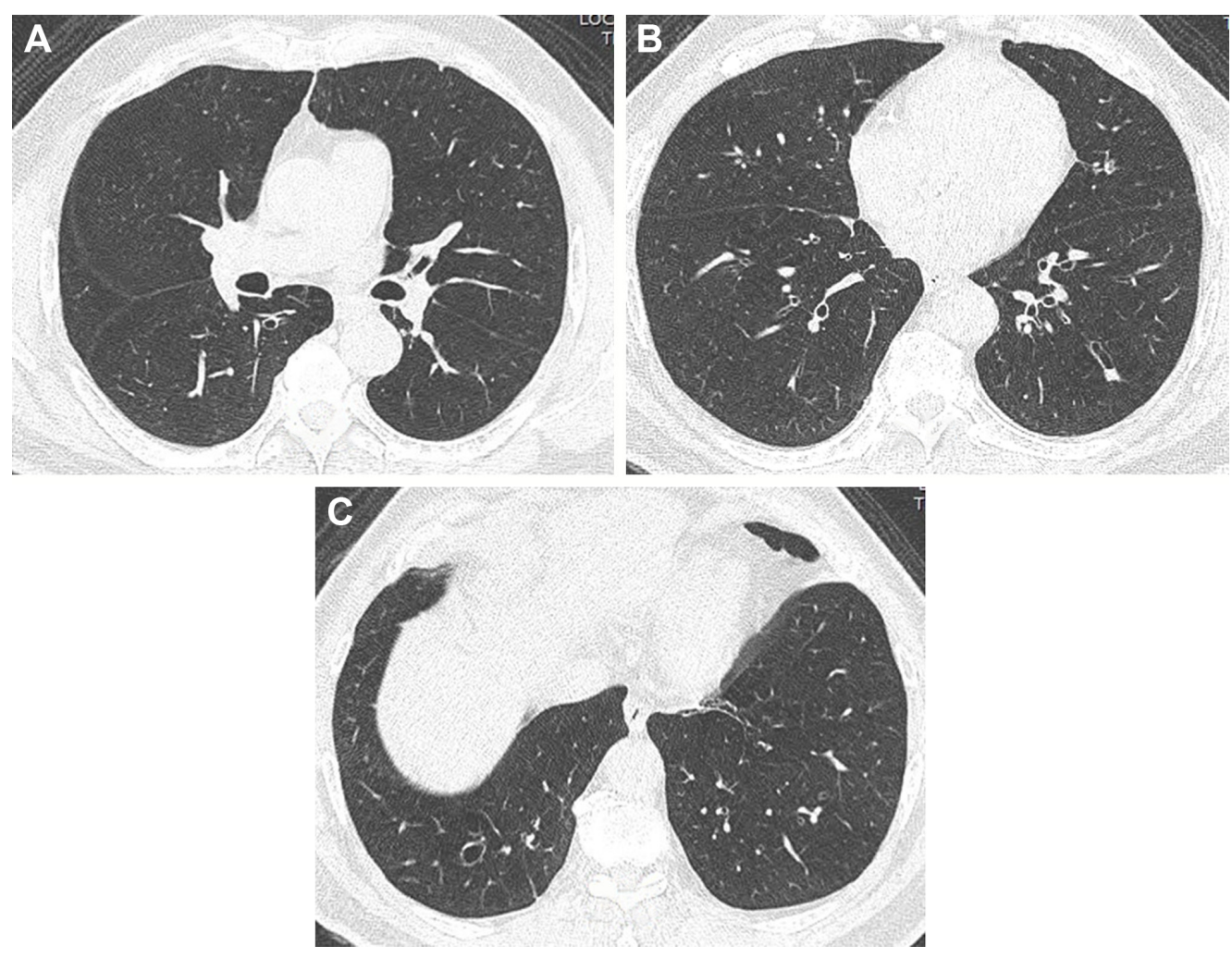

Figure 2 Axial CT images with a lung-window setting showing tubular bronchiectasis with the signet ring sign in the right lower lobe (A-C) and the tram-track sign in the left lower lobe (B).

Abbreviation: $\mathrm{CT}$, computed tomography.

for airway inflammation that causes bronchiectasis. ${ }^{25} \mathrm{We}$ found no significant association between lower airway bacterial colonization and bronchiectasis; however, bacterial load in sputum may be lower than the detectable threshold with conventional culture media used in routine microbiological tests. The radiometric culture method may improve detection sensitivity for bacterial load in airway of patients affected by COPD. However, the clinical significance and therapeutic implications of bacterial colonization of the airway demand further investigation. ${ }^{26,27}$ Owing to structural abnormalities and inhaled corticosteroid-associated local immunosuppression, both tuberculosis and non-tuberculous mycobacterial infection are common in bronchiectasis and COPD ${ }^{28,29}$ However, we were unable to detect a high prevalence of mycobacterial infection in the Thai COPD cohort with bronchiectasis. In addition, the presence of colonized
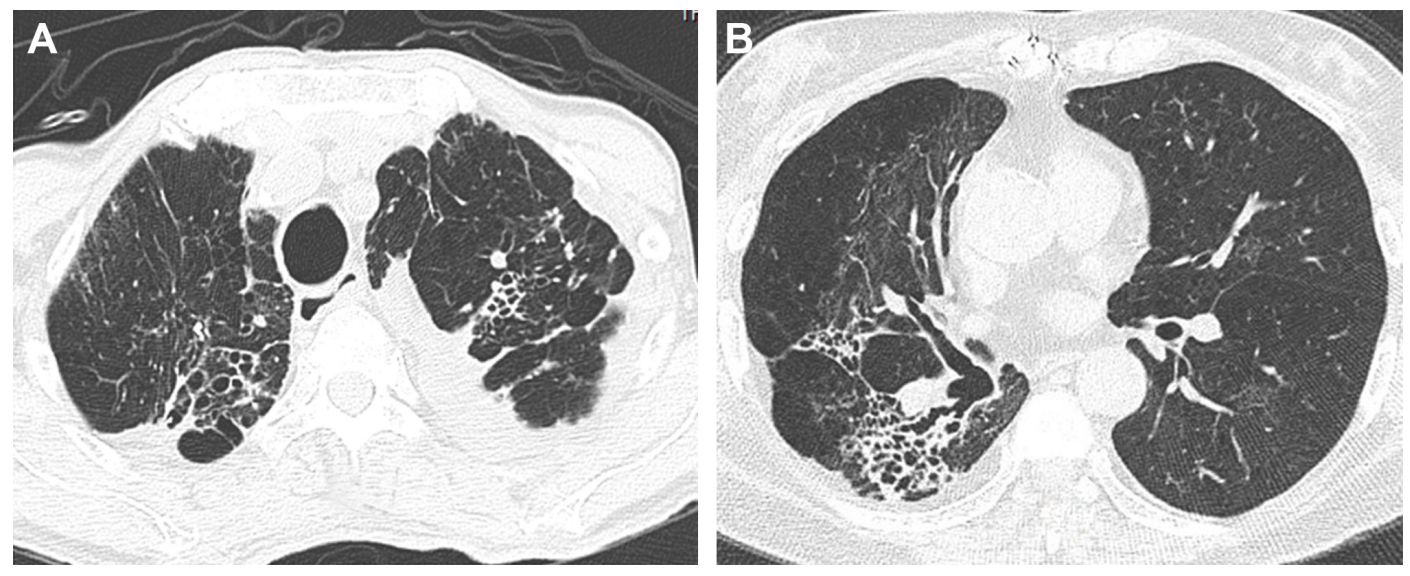

Figure 3 Axial CT images with a lung-window setting showing combined tubular and varicose bronchiectasis, emphysema and fibrosis in bilateral upper lobes (A), right middle lobe (B) and right lower lobe (B).

Abbreviation: CT, computed tomography. 

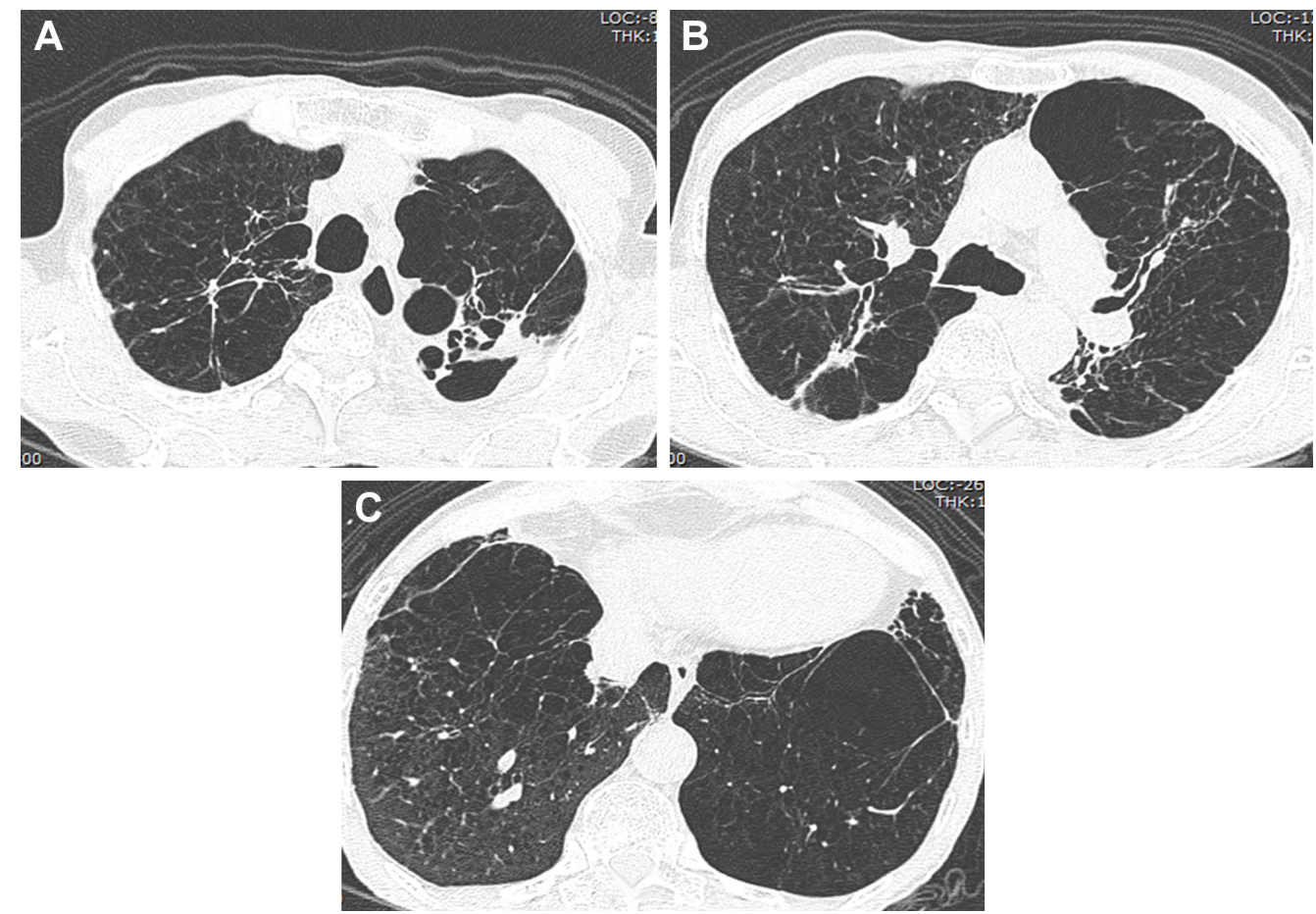

Figure 4 Axial CT images with a lung-window setting showing severe centrilobular emphysema and bronchiectasis in both lungs (A-C) Abbreviation: $\mathrm{CT}$, computed tomography.

mycobacterial infection has to be cautiously interpreted within the clinical and radiological context. Hazardous effect of inhaled corticosteroids on COPD with frequent exacerbation in the presence of mycobacterial airway infection is of concern. $^{29}$

Coronary artery calcification can be identified using CT scan, and this finding is characteristic of coronary atherosclerosis. The coronary artery calcium score (CACS) has been used for identifying and stratifying risk for coronary artery diseases and it correlates with mortality. ${ }^{30}$ In this study,

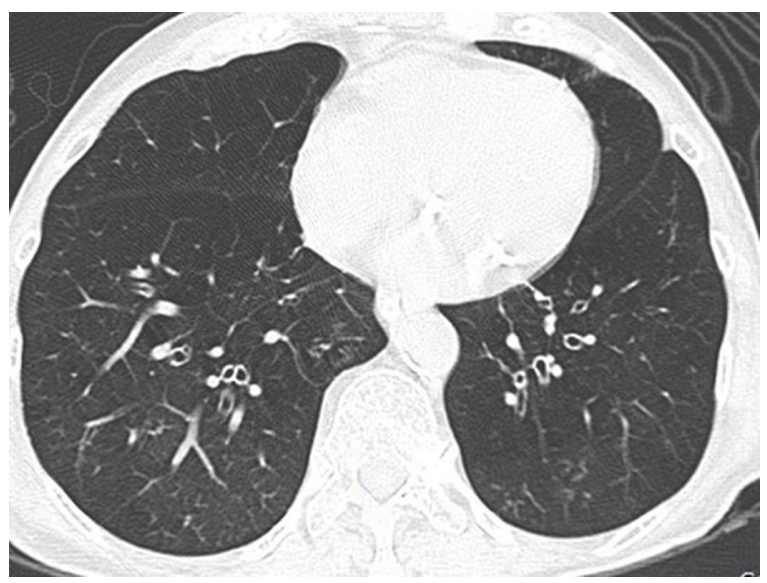

Figure 5 Axial CT image with a lung-window setting showing emphysema and bronchial wall thickening in bilateral lower lobes.

Abbreviation: CT, computed tomography. coronary calcification was common; however, we did not evaluate the CACS. Additionally, coronary calcification was not associated with COPD symptoms evaluated using CAT scores. By contrast, Williams et al found the median CACS to be higher in smokers than in normal subjects. It also correlates with 6-minute walking distance and mMRC scale. ${ }^{31}$ Thus, CACS may be used to determine cardiovascular cause of dyspnea in COPD. ${ }^{32}$

Patients with concurrent COPD and bronchiectasis may have a unique phenotype that is prone to more severe and frequent exacerbation. CT may be used to diagnose bronchiectasis in patients with frequent COPD exacerbations. It may also be applied in patients with cough and sputum production, which cannot be clinically distinguished from chronic bronchitis phenotype. This combination of two airway diseases is associated with poor prognosis. The detection of bronchiectasis using novel imaging techniques, provides an opportunity for early identification and therapeutic intervention aimed at improving the outcome for COPD patients.

\section{Conclusions}

The prevalence of CT-detected bronchiectasis was common in the investigated Thai COPD patients. Bronchiectasis was associated with frequent exacerbation or hospitalization related to exacerbation in the previous year. However, 

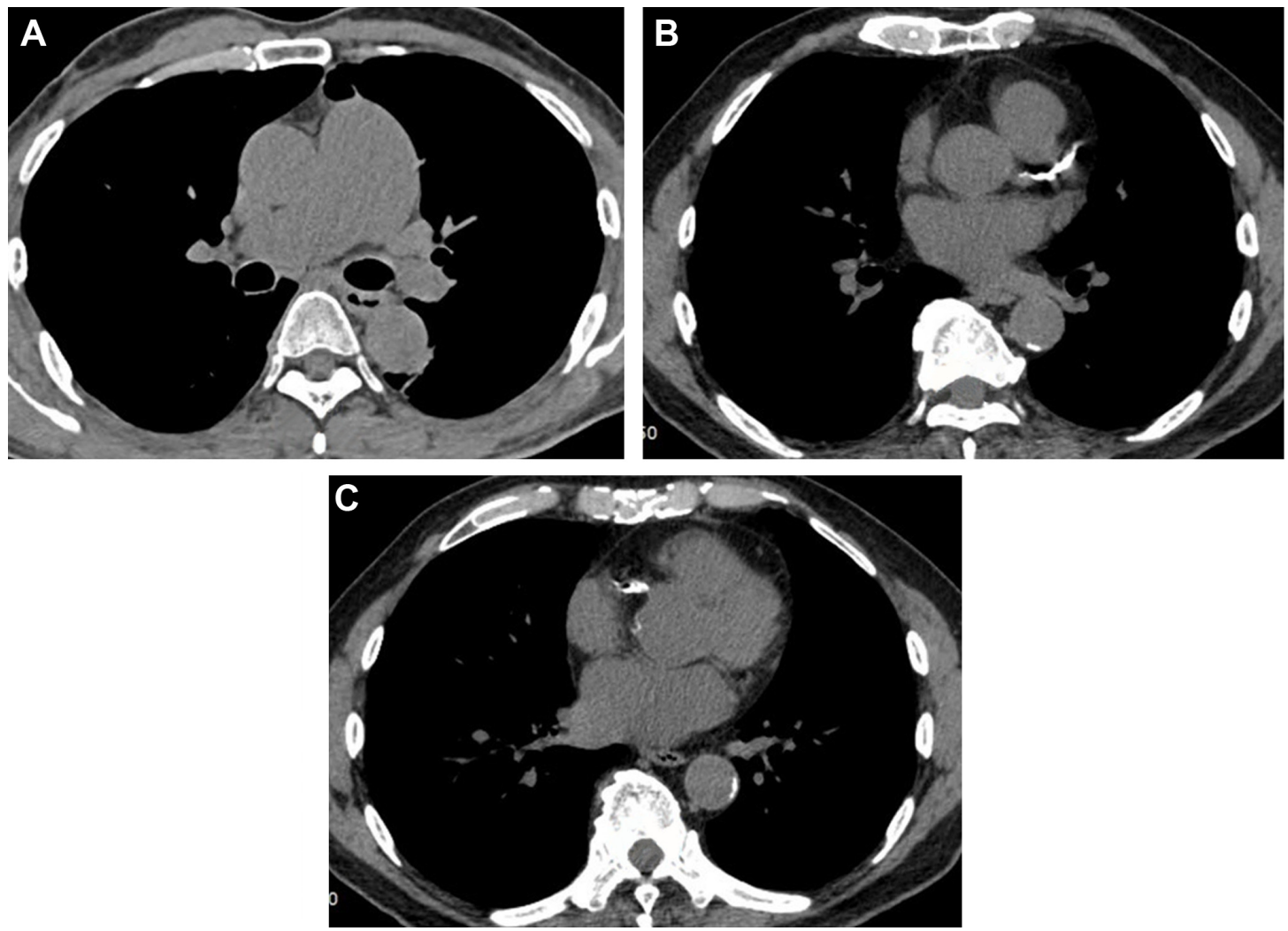

Figure 6 Axial CT images with a mediastinal-window setting showing a dilated main pulmonary artery (A) and calcifications of the aorta and coronary arteries (B-C). Abbreviation: CT, computed tomography.

the physiological derangement did not significantly differ between COPD patients with and without bronchiectasis. Tuberculosis is endemic in Thailand; however, the presence of tuberculosis was uncommon in Thai COPD patients with bronchiectasis.

Table 5 Other CT findings among COPD patients

\begin{tabular}{ll}
\hline CT findings & \multicolumn{1}{c}{$\begin{array}{l}\text { Frequency, } \\
\text { n (\%) }\end{array}$} \\
\hline Parenchymal lung abnormalities (decreased lung attenuation) \\
Pulmonary emphysema & $59(81.9)$ \\
Centrilobular emphysema & $52(88.13)$ \\
Paraseptal emphysema & $34(57.62)$ \\
Panlobular emphysema & $14(23.72)$ \\
Parenchymal lung abnormalities (increased lung attenuation) & $62(86.11)$ \\
$\quad$ Solid and ground-glass pulmonary nodules & \\
Small airway abnormalities & $10(13.89)$ \\
Tree-in-bud appearance (centrilobular nodules and & \\
bronchiolectasis) & $48(66.67)$ \\
Air trapping & $10(13.89)$ \\
Large airway abnormalities & \\
$\quad$ Tracheobronchomalacia & $14(19.4)$ \\
Extra-pulmonary and vascular abnormalities & $67(93.05)$ \\
Lymph node enlargement & $60(83.33)$ \\
Calcified aorta & $13(18.05)$ \\
Coronary artery calcification & \\
Pulmonary hypertension &
\end{tabular}

Abbreviation: CT, computed tomography.

\section{Acknowledgments}

We thank Dr Pawin Numthavaj, MD, PhD (Division of Biostatistics and Clinical Epidemiology, Faculty of Medicine Ramahibodi Hospital, Mahidol University) for statistical analysis.

This abstract was presented by my colleague (Dr Jitsupa Onnipa) with the interim finding. The poster abstract was presented at the 2nd International Workshop on Lung Health. COPD: New Challenges, New Solutions Valencia, 19-21 February 2015, p 35.

\section{Disclosure}

The authors report no conflicts of interest in this work.

\section{References}

1. Murray CJ, Lopez AD. Mortality by cause for eight regions of the world: Global Burden of Disease Study. Lancet. 1997;349(9061):1269-1276.

2. Anzueto A. Impact of exacerbations on COPD. Eur Respir Rev. 2010; 19(116):113-118.

3. Hurst JR, Vestbo J, Anzueto A, et al. Susceptibility to exacerbation in chronic obstructive pulmonary disease. $N$ Engl J Med. 2010;363(12): $1128-1138$

4. Global Strategy for the Diagnosis, Management and Prevention of COPD. 2014. Available from: www.goldcopd.com/guidelines-global-strategyfor-diagnosis-management.html. Accessed January 23, 2014.

5. Rodriguez-Roisin R. Toward a consensus definition for COPD exacerbations. Chest. 2000;117(5 Suppl 2):398S-401S. 
6. Kim V, Han MK, Vance GB, et al. The chronic bronchitic phenotype of COPD: an analysis of the COPDGene Study. Chest. 2011;140(3): 626-633.

7. Barker AF. Bronchiectasis. N Engl J Med. 2002;346(18):1383-1393.

8. O'Donnell AE. Bronchiectasis in patients with COPD: a distinct COPD phenotype? Chest. 2011;140(5):1107-1108.

9. Novosad SA, Barker AF. Chronic obstructive pulmonary disease and bronchiectasis. Curr Opin Pulm Med. 2013;19(2):133-139.

10. McGuinness G, Naidich DP. CT of airways disease and bronchiectasis. Radiol Clin North Am. 2002;40(1):1-19.

11. Han MK, Agusti A, Calverley PM, et al. Chronic obstructive pulmonary disease phenotypes: the future of COPD. Am J Respir Crit Care Med. 2010;182(5):598-604.

12. Cole PJ. Inflammation: a two-edged sword - the model of bronchiectasis. Eur J Respir Dis Suppl. 1986;147:6-15.

13. Agusti A, Calverley PM, Celli B, et al. Characterisation of COPD heterogeneity in the ECLIPSE cohort. Respir Res. 2010;11(1):122.

14. Whitters D, Stockley RA. Bronchiectasis in older patients with chronic obstructive pulmonary disease: prevalence, diagnosis and therapeutic management. Drugs Aging. 2013;30(4):215-225.

15. Palwatwichai A, Chaoprasong C, Vattanathum A, Wongsa A, Jatakanon A. Clinical, laboratory findings and microbiologic characterization of bronchiectasis in Thai patients. Respirology. 2002;7(1):63-66.

16. Standardization of Spirometry, 1994 Update. Am J Respir Crit Care Med. 1995;152(3):1107-1136.

17. Anthonisen NR, Manfreda J, Warren CP, Hershfield ES, Harding GK, Nelson NA. Antibiotic therapy in exacerbations of chronic obstructive pulmonary disease. Ann Intern Med. 1987;106(2):196-204.

18. Jones PW, Harding G, Berry P, Wiklund I, Chen WH, Kline Leidy N. Development and first validation of the COPD Assessment Test. Eur Respir J. 2009;34(3):648-654.

19. Lee SD, Huang MS, Kang J, et al. The COPD assessment test (CAT) assists prediction of COPD exacerbations in high-risk patients. Respir Med. 2014;108(4):600-608.

20. Bestall JC, Paul EA, Garrod R, Garnham R, Jones PW, Wedzicha JA. Usefulness of the Medical Research Council (MRC) dyspnoea scale as a measure of disability in patients with chronic obstructive pulmonary disease. Thorax. 1999;54(7):581-586.

21. Hansell DM, Bankier AA, MacMahon H, McLoud TC, Müller NL, Remy J. Fleischner society: glossary of terms for thoracic imaging. Radiology. 2008;246(3):697-722.
22. Zhang G, David A, Wiedmann TS. Performance of the vibrating membrane aerosol generation device: aeroneb micropump nebulizer. J Aerosol Med. 2007;20(4):408-416.

23. Sheehan RE, Wells AU, Copley SJ, et al. A comparison of serial computed tomography and functional change in bronchiectasis. Eur Respir J. 2002;20(3):581-587.

24. Martinez-Garcia MA, Soler-Cataluna JJ, Donat Sanz Y, et al. Factors associated with bronchiectasis in patients with COPD. Chest. 2011; 140(5):1130-1137.

25. Donaldson GC, Seemungal TAR, Bhowmik A, Wedzicha JA. Relationship between exacerbation frequency and lung function decline in chronic obstructive pulmonary disease. Thorax. 2002;57(10):847-852.

26. Sharma S, Anthonisen N. Role of antimicrobial agents in the management of exacerbations of COPD. Treat Respir Med. 2005;4(3):153-167.

27. van Alphen L, Jansen HM, Dankert J. Virulence factors in the colonization and persistence of bacteria in the airways. Am J Respir Crit Care Med. 1995;151(6):2094-2099.

28. Chan ED, Iseman MD. Underlying host risk factors for nontuberculous mycobacterial lung disease. Semin Respir Crit Care Med. 2013;34(1): 110-123.

29. Dong $\mathrm{YH}$, Chang $\mathrm{CH}$, Lin Wu FL, et al. Use of inhaled corticosteroids in patients with COPD and the risk of TB and influenza: a systematic review and meta-analysis of randomized controlled trials. Chest. 2014; 145(6):1286-1297.

30. Greenland P, Bonow RO, Brundage BH, et al. ACCF/AHA 2007 clinical expert consensus document on coronary artery calcium scoring by computed tomography in global cardiovascular risk assessment and in evaluation of patients with chest pain: a report of the American College of Cardiology Foundation Clinical Expert Consensus Task Force (ACCF/AHA Writing Committee to Update the 2000 Expert Consensus Document on Electron Beam Computed Tomography) developed in collaboration with the Society of Atherosclerosis Imaging and Prevention and the Society of Cardiovascular Computed Tomography. J Am Coll Cardiol. 2007;49(3):378-402.

31. Lange P, Marott JL, Vestbo J, et al. Prediction of the clinical course of chronic obstructive pulmonary disease, using the new GOLD classification: a study of the general population. Am J Respir Crit Care Med. 2012;186(10):975-981.

32. Williams MC, Murchison JT, Edwards LD, et al. Coronary artery calcification is increased in patients with COPD and associated with increased morbidity and mortality. Thorax. 2014;69(8):718-723.
International Journal of COPD

\section{Publish your work in this journal}

The International Journal of COPD is an international, peer-reviewed journal of therapeutics and pharmacology focusing on concise rapid reporting of clinical studies and reviews in COPD. Special focus is given to the pathophysiological processes underlying the disease, intervention programs, patient focused education, and self management protocols.

\section{Dovepress}

This journal is indexed on PubMed Central, MedLine and CAS. The manuscript management system is completely online and includes a very quick and fair peer-review system, which is all easy to use. Visit http://www.dovepress.com/testimonials.php to read real quotes from published authors. 